Article

\title{
Structural and Chemical Hierarchy in Hydroxyapatite Coatings
}

\author{
Karlis A. Gross ${ }^{1}$, Christiane Petzold ${ }^{2}$, Liene Pluduma-LaFarge ${ }^{1}$, Maris Kumermanis ${ }^{1}$ \\ and Håvard J. Haugen ${ }^{3, * \mathbb{D}}$ \\ 1 Biomaterials Research Laboratory, Riga Technical University, Faculty of Materials Science and Applied \\ Chemistry, LV-1048 Riga, Latvia; kgross@rtu.lv (K.A.G.); liene.pluduma@gmail.com (L.P.-L.); \\ mariskum@inbox.lv (M.K.) \\ 2 Leibniz-Institute for New Materials, 66123 Saarbrücken, Germany; Christiane.Petzold@leibniz-inm.de \\ 3 Department of Biomaterials, Institute for Clinical Dentistry, Faculty of Dentistry, University of Oslo, \\ 0455 Oslo, Norway \\ * Correspondence: h.j.haugen@odont.uio.no; Tel.: +47-228-5210
}

Received: 16 September 2020; Accepted: 2 October 2020; Published: 7 October 2020

\begin{abstract}
Hydroxyapatite coatings need similarly shaped splats as building blocks and then a homogeneous microstructure to unravel the structural and chemical hierarchy for more refined improvements to implant surfaces. Coatings were thermally sprayed with differently sized powders (20-40, 40-63 and 63-80 $\mu \mathrm{m}$ ) to produce flattened homogeneous splats. The surface was characterized for splat shape by profilometry and Atomic force microscopy (AFM), crystal size by AFM, crystal orientation by X-ray diffraction (XRD) and structural variations by XRD. Chemical composition was assessed by phase analysis, but variations in chemistry were detected by XRD and Raman spectroscopy. The resulting surface electrical potential was measured by Kelvin probe AFM. Five levels of structural hierarchy were suggested: the coating, the splat, oriented crystals, alternate layers of oxyapatite and hydroxyapatite (HAp) and the suggested anion orientation. Chemical hierarchy was present over a lower range of order for smaller splats. Coatings made from smaller splats exhibited a greater electrical potential, inferred to arise from oxyapatite, and supplemented by ordered $\mathrm{OH}^{-}$ions in a rehydroxylated surface layer. A model has been proposed to show the influence of structural hierarchy on the electrical surface potential. Structural hierarchy is proposed as a means to further refine the properties of implant surfaces.
\end{abstract}

Keywords: electrical surface potential; hydroxyapatite coating; design; implants; self-assembly; hierarchy; biomaterials

\section{Introduction}

When an implant is placed into the human body, the surface determines the interaction with the biological system and further integration. Thus, hydroxyapatite coatings on bone implants play a critical role for the integration with bone, and so consideration needs to be directed to the surface characteristics. Surface features include topography [1-5], chemistry [6-8] and charge [9,10]; these measures must be quantified at the micro-and nano-level [11-13]. Detailed surface characterization will show how thermal spraying can change the topography and surface electrical potential of hydroxyapatite coatings, and how the design of joint replacement surfaces could include a consideration of chemical and structural hierarchy [14].

The surface topography/texture of a hydroxyapatite made by thermal spraying can be explained by focusing on the building blocks of the coatings-individual splats. An incompletely melted particle can produce a raised center if the core remains intact or a micro-rough splat if the particle core fractures 
upon impact, Figure 1. Both types of splats will introduce variations to the splat topography and microstructure. A homogeneous splat is needed from a completely melted particle to provide the best starting point for producing a homogeneous coating to allow optimization of the surface.

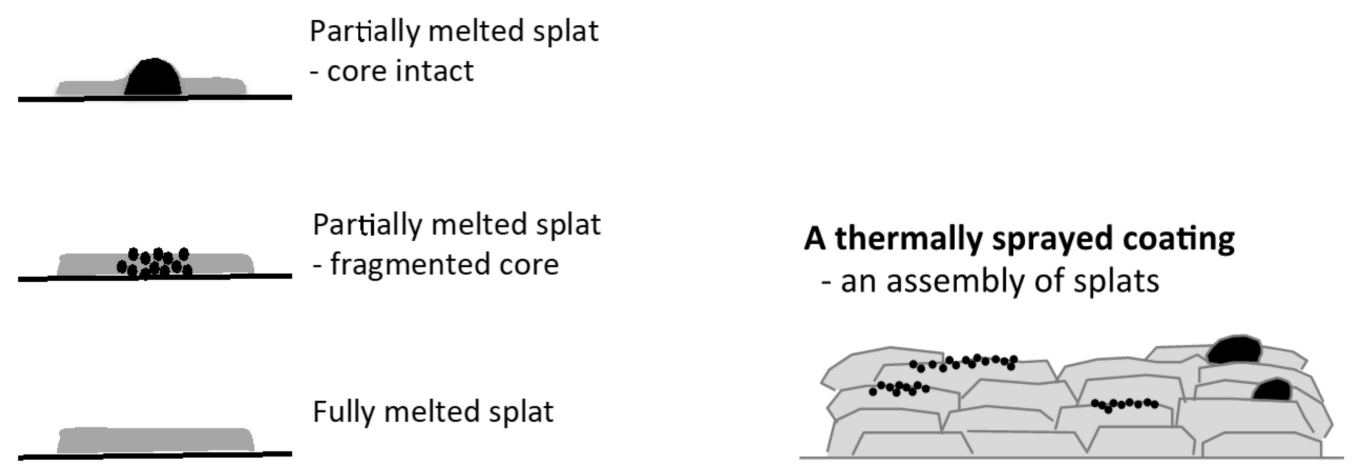

Figure 1. The variety of splats displaying the building block and their assembly in a thermal spray coating: a splat with a raised center from a partially melted particle, a micro-rough splat from a partially melted particle and a smooth splat from a melted particle. Black represents the unmelted particle fraction.

A homogeneous splat - the reproducible building block for coatings-will allow further design of the coating. Although the standard for orthopedic coatings requires the crystallinity to be above a threshold [15], hydroxyapatite can be made amorphous [16] or completely crystalline [17]. The uniformity is key for reproducibility of properties and performance as well as further optimization of the microstructure. The goal is to create a more uniform coating from the complete melting of particles, and apply Kelvin probe atomic force microscopy to probe for differences stemming from the change in microstructure.

In this work, we will characterize the structure (topography, splat, crystal size) and chemistry of thermally sprayed hydroxyapatite coatings made from powders of three different particle size distributions, to explore the change in topography and electrical potential. We hypothesize that smaller powder particles will result in a more homogeneous coating due to more uniform particle heating in the thermal spray plume. Structural hierarchy will be illustrated within crystals, splats and the coating. We suspect a different hierarchy for smaller particles than for larger particles. The objective is to show the formation of a homogeneous building block, and reveal a structural hierarchy that could be used for improvements in hydroxyapatite-coated implants.

\section{Materials and Methods}

Analysis of the coating surface and not single splats on metal is necessary to report on the surface characteristics of an implant surface. Earlier studies focused on single splats collected on substrates from a "wipe test" [18] or from passing through a fine aperture [19,20]. Splats solidified on metallic substrates do not represent the shape, nor the microstructure of splats solidified on previously deposited hydroxyapatite splats. Melted hydroxyapatite powder particles offer the potential to spread out better on previously deposited splats due to (a) an increased wettability, and (b) a lower thermal conductivity of previously deposited hydroxyapatite [21]. Therefore, the investigation will be on a coating instead of single splats, that have a different microstructure.

\subsection{Coating Preparation}

Coatings were flame-sprayed with spray-dried HAp powder (CAM Bioceramics, Leiden, The Netherlands). Powder was classified by wet sieving to three different particle size distributions (20-40 $\mu \mathrm{m}, 40-63 \mu \mathrm{m}$ and 63-80 $\mu \mathrm{m}$ ), dried and then re-sieved to restore powder flowability. The powder was transported in a dry-air carrier gas to a flame in the Metco 6P flame spray torch (Sulzer-Metco, 
Winterthur, Switzerland) ) fuelled by oxygen and acetylene gas. Coatings were made on grit-blasted pure titanium substrates.

Based on conditions for producing melted particles, a spray distance of 10, 12 and $15 \mathrm{~cm}$ was chosen for the $20-40 \mu \mathrm{m}, 40-63 \mu \mathrm{m}$ and $63-80 \mu \mathrm{m}$ powder, respectively. The larger particles required a longer residence time for melting the larger particle volume. A preheat of $400^{\circ} \mathrm{C}$ was chosen since it exceeds the $100{ }^{\circ} \mathrm{C}$ temperature for making rounded splats [17] and also attains the $400{ }^{\circ} \mathrm{C}$ required to prevent moisture adsorption [22] during the coating process.

\subsection{Measurement of Purity, Phase Composition and Surface Electrical Potential}

Phase and chemistry were measured over two length scales. X-ray diffraction provided a global assessment of coating surface, but micro-Raman spectroscopy probed the bonding at the micron-sized level. Trace elements in the hydroxyapatite were detected using a SCIEX ELAN DRC-inductively coupled plasma-mass spectrometer (ICP-MS) (PerkinElmer, Waltham, MA, USA). Argon with a purity of $99.999 \%$ was used as a carrier gas (AGA, Riga, Latvia). The powder with a weight of $0.3 \mathrm{~g}$ was digested in an oxidizing acidic medium consisting of $65 \%$ nitric acid (Suprapur, Merck, Darmstad, Germany) and 30\% hydrogen peroxide (Suprapur, Merck, Darmstad, Germany) and then homogenized in an ultrasonic bath (Sonorex RK100 BANDELIN electronic GmbH and Co. KG, Berlin, Germany). Mineralization was carried out in a closed vessel microwave digestion system (Anton Paar 300, Anton Paar GmbH, Graz, Austria). A total of 5 measurements were taken and the average value calculated.

X-ray powder diffraction (XRD) checked for preferred crystal orientation and confirmed phase purity. For crystal orientation, characterization was conducted on the coating to see if a change occurred in the relative peak intensities. To determine the phase purity, a random crystal orientation was preferred and so the coating was triturated to a fine powder in a mortar and pestle before conducting XRD. X-ray diffraction patterns were obtained by a D8 ADVANCE diffractometer (Bruker Corporation, Billerica, MA, USA) recorded from $5^{\circ}$ to $60^{\circ}$ using $\mathrm{Cu} \mathrm{K} \alpha$ radiation $(\lambda=1.54180 \AA$ generated at $40 \mathrm{~mA}$ and $40 \mathrm{kV}$ ) at a $0.02^{\circ}$ step size.

Raman spectra were obtained by the InVia micro-Raman spectrometer (Renishaw, Wotton-under-Edge, Gloucestershire, United Kingdom) with a He-Ne $(633 \mathrm{~nm})$ red laser excitation through a $1800 \mathrm{~mm}^{-1}$ grating in a backscattering geometry. The laser was operated at $10 \mathrm{~mW}$. The spectrometer was calibrated with silicon, giving a Raman line at $520 \mathrm{~cm}^{-1}$. Spectra were acquired for $40 \mathrm{~s}$ from the center of the splat, and at opposite sides on the outer edge of the splat. Spectra were normalized by multiplying all intensity values with a factor to reduce the left peak at $446 \mathrm{~cm}^{-1}$ to unity. This would allow any variations in the $\mathrm{OH}^{-}$content at $963 \mathrm{~cm}^{-1}$ to be readily detected.

An atomic force microscope (Solver-Pro NT-MDT, Moscow, Russia) with a Kelvin probe force microscopy function measured the surface electrical potential. Five measurements were obtained for each sample and the average value was calculated. The size of each scan was $2 \times 2 \mu \mathrm{m}$. Each image consisted of $256 \times 256$ data points. A semicontact method was used. The average electrical potential value was calculated for each sample from the average of each scan.

\subsection{Measurement of Micro- and Nano-Topography}

Topography was assessed over two length scales with stylus/probe measurement methods. Profilometry, as the conventional surface engineering method, determined the splat shape at a larger length scale, while atomic force microscopy measured more detail of the splat edge and splat surface.

Profilometry was performed (Talysurf Intra 50 contact profilometer, Taylor-Hobson, Leicester, England) with a spherical stylus of $2 \mu \mathrm{m}$ diameter and an included angle of $90^{\circ}$. A map with an area of $200 \times 200 \mu^{2}(400 \times 400$ data points) was produced by TalyMap Expert software (Taylor Hobson, Elancourt, France) as a 3D view or a photosimulation. The topography was plotted in a $2 \mathrm{D}$ view with a corresponding line profile. 
The height of selected splats was determined from line profiles made through the center of the splat by measuring the vertical distance between the reference baseline outside of the splat and the highest point on the splat. Line profiles were made at $45^{\circ}$ incremental rotations and an average calculated from profiles collected at 8 different rotations. This was easily conducted for the $20-40 \mu \mathrm{m}$ source powder, but the large splat area resulting from the larger particle sizes made it difficult to determine a baseline, and so the splat height for the largest particle sizes was not calculated.

Topography of thermal spray HAp coatings was analyzed with an atomic force microscope (MFP 3D; Asylum Research, Santa Barbara, USA) in air with fast scan direction perpendicular to the cantilever (probes: OMCL-AC160TS-W2, Olympus Optical Co. Ltd., Tokyo, Japan) to avoid buckling. Height of the individual splats and HAp crystal size on the splat surfaces were analyzed. Splat heights were determined from profiles of scans of $50 \mu \mathrm{m} \times 50 \mu \mathrm{m}(\mathrm{N}=23)$ from splats of the 3 groups. Height differences were measured from the smoothened profile data ( $\mathrm{N}=119$ edges). For crystal size analysis, entire splats of the group $20-40 \mu \mathrm{m}$ were imaged at $50 \mu \mathrm{m} \times 50 \mu \mathrm{m}(\mathrm{N}=5)$. Subsequently, the AFM tip was positioned in the center (C), edge (E) or transition zone (T) of the splat. The positions were assigned for each splat individually based on the previous scan at $50 \mu \mathrm{m} \times 50 \mu \mathrm{m}$, Figure 2 . On each position, two images were scanned: $1 \times 1 \mu \mathrm{m}^{2}$ and $5 \times 5 \mu \mathrm{m}^{2}$. The image centers were defined as follows: $\mathrm{C}-$ center of the splat, $\mathrm{E}-3 \mu \mathrm{m}$ from the border of the splat, $\mathrm{T}=(\mathrm{C}-\mathrm{E}) / 2$. The distance between the centers of the scans at the respective positions was between $8 \mu \mathrm{m}$ and $10 \mu \mathrm{m}$ : splat sizes were chosen such that the scan areas of $C, T$ and $E$ would not overlap. Crystal sizes were measured with Gwyddion (Version 2.3, http://gwyddion.net) from the image sized $1 \times 1 \mu \mathrm{m}^{2}$ or $5 \times 5 \mu \mathrm{m}^{2}$, depending on the crystal size and correlated to their respective positions.

\subsection{Statistics}

All data were analyzed with Origin 8.5 (Origin Lab Inc. Northampton, MA, USA). The significance was determined with One Way ANOVA in case of normally distributed data, or Kruskal-Wallis One Way Analysis of Variance on Ranks in case of nonparametric data. The results are given as median \pm interquartile range (IQR). Statistical significance is indicated as $P<0.05$.

\section{Results}

\subsection{Purity and Phase Analysis}

All coatings made from the differently sized particles exhibited oriented hydroxyapatite crystals within splats. For a random crystal orientation, the most intense peak in the XRD pattern was expected at $31.8^{\circ}$, but the highest peak at $26.1^{\circ}$ indicated oriented crystals, as the diffraction condition was only satisfied for crystals with a $<00 l>$ alignment, Figure $2 \mathrm{~A}$. The next most intense XRD peak located at $53.1^{\circ}$ originated from the same crystal orientation. The most intense peak stemmed from the (002) crystal planes, indicating diffraction from half the height of the unit cell, but the second peak associated with the (004) crystal plane originated from diffraction within a quarter of the unit cell height. Given the definition of crystallinity for thermal spray coatings based on the amount of crystalline material where amorphous and crystalline phase may be present [16], this diffraction pattern represented a $100 \%$ crystalline coating, with crystals oriented such that the $<00 l>$ direction was perpendicular to the surface.

The crushed and triturated coatings showed peaks characteristic of an apatite phase, indicating that only apatite is present in the textured coating. The (002) peak appeared at a slightly greater intensity than expected for a complete random crystal orientation but this did not deter us from seeing that only apatite was present (the (002) peak should be at $25 \%$ intensity compared to the most intense (211) peak at $\left.31.8^{\circ}\right)$, Figure $2 \mathrm{~B}$. 
A

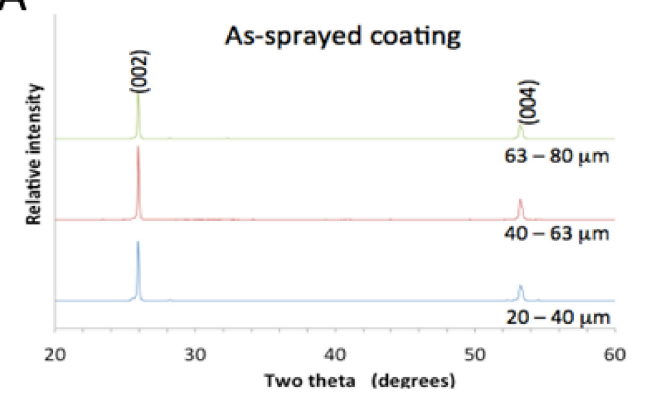

B

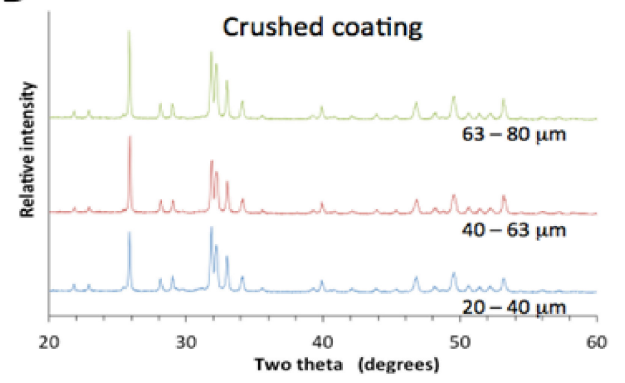

Figure 2. X-ray diffraction of (A) coatings showing a $<001>$ crystal orientation and of (B) crushed coatings displaying peaks characteristic of hydroxyapatite. Coatings were made from $20-40 \mu \mathrm{m}$ powder, 40-60 $\mu \mathrm{m}$ powder and 60-80 $\mu \mathrm{m}$ powder.

Purity of the coating was reported in terms of the trace elements and the $\mathrm{Ca} / \mathrm{P}$ molar ratio. Hydroxyapatite contained few trace elements as shown by the ICP-MS results. The largest concentrations above 1 ppm included $68.1 \mathrm{ppm} \mathrm{Sr}, 5.2 \mathrm{ppm} \mathrm{Ni}, 4.0 \mathrm{ppm} \mathrm{Mn}, 1.3 \mathrm{ppm}$ Ba and $1.2 \mathrm{ppm} \mathrm{Zn}$. The $\mathrm{Ca} / \mathrm{P}$ molar ratio based on the X-ray diffraction and the absence of impurity phases [23] was deemed as 1.67 .

A detailed examination of the Raman peak centered at $955 \mathrm{~cm}^{-1}$ indicated the presence of oxyapatite (OAp). This was supported by the doublet in the (004) XRD peak that was seen at about $53.3^{\circ}$, Figure 3. The left shoulder represented oxyapatite [24] and was more intense for the coating made from finer powder (compared to XRD of coatings made from 20-40 $\mu \mathrm{m}$ powder and $63-80 \mu \mathrm{m}$ powder). The Raman spectra showed a peak at $963 \mathrm{~cm}^{-1}$, assigned to hydroxyapatite, and a peak at $946 \mathrm{~cm}^{-1}$, representing oxyapatite [25]. The hydroxyl peak was $31 \%$ more intense than the oxyapatite peak for the coatings made from the smaller powder fractions, but $44 \%$ more intense for the largest powder.
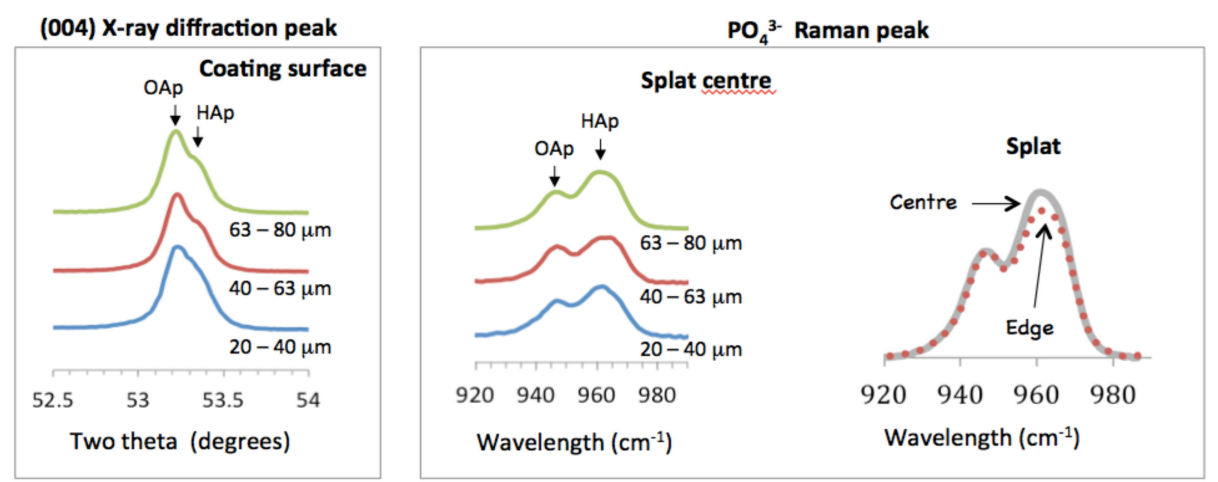

Figure 3. Oxyapatite and hydroxyapatite shown in X-ray diffraction patterns and Raman spectra. The oxyapatite peak was normalized in both the X-ray diffraction patterns and Raman spectra for ease of comparison. Raman spectra for the coatings were obtained from the middle of the splat. Raman spectra from the large splat made from $63-80 \mu \mathrm{m}$ powder was taken in the center $(-)$ and edge $(\cdots)$ of the splat.

Raman spectroscopy showed that the hydroxyl concentration in splats was higher at the center than at the rim of the splats. For the coating made from the smallest powder $(20-40 \mu \mathrm{m})$, the $963 \mathrm{~cm}^{-1}$ peak height was 35\% more intense relative to the $946 \mathrm{~cm}^{-1}$ peak height. At the edge of the splat, the $963 \mathrm{~cm}^{-1}$ peak height was $31 \%$ more intense on opposite ends of the splat. This showed that the splat could have contained a lower $\mathrm{OH}^{-}$concentration at the edge compared to the splat center, Figure 3. This effect was clearly shown for splats made from larger particles. For the coating made from $63-80 \mu \mathrm{m}$ powder, the hydroxyapatite peak $\left(\right.$ at $963 \mathrm{~cm}^{-1}$ ) at the center was $52 \%$ relative to the oxyapatite peak (at $946 \mathrm{~cm}^{-1}$ ), but only $40 \%$ on opposite ends of the splat. 


\subsection{Electrical Surface Potential}

The surface electrical potential measured by Kelvin probe atomic force microscopy showed a change with particle size. Coatings made from a smaller particle size gave the largest surface electrical potential. There was a noticeable drop with coatings made from larger particles (both the 40-60 $\mu \mathrm{m}$ and 60-80 $\mu \mathrm{m}$ powders). The largest particle size gave the smallest surface potential, Figure 4 . Since the crystal size was similar for all the coatings (see Table 1), the difference is not related to crystal size or grain boundary area.

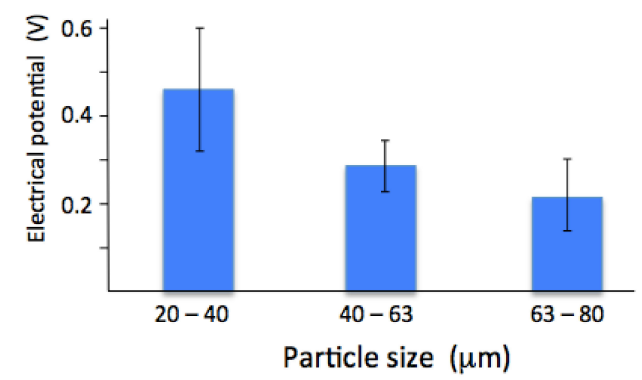

Figure 4. Electrical surface potential measured by Kelvin probe AFM on coatings made from $20-40 \mu \mathrm{m}$, 40-60 $\mu \mathrm{m}$ and $60-80 \mu \mathrm{m}$ powder.

\subsection{Splat Topography—Height, Edge Geometry and Flatness}

Splats populating the three different coatings were rounded, as opposed to splashed splats that have an erratic circumference, and more prevalent in plasma-sprayed coatings. The smaller splats were identified and measured with the most ease; larger splats overlapped more frequently and were more commonly covered with smaller splats. Most splats were circular, but some exhibited an elongated shape from the underlying terrain. The unevenness of the coating surface is best viewed in the 3D map (Figure 5a), but the splat shape is best surveyed in the photosimulated view of the coating, Figure 5b.

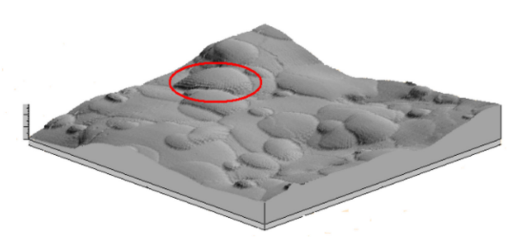

(a) 3D map

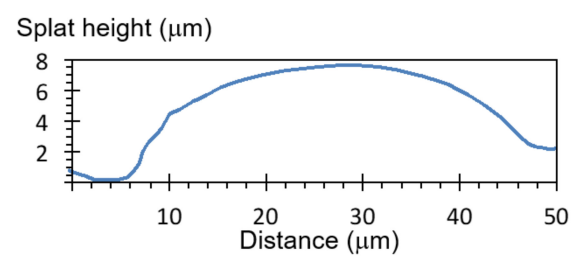

(c) Splat profile

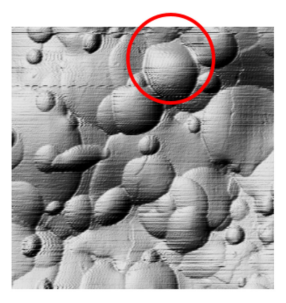

(b) photosimulation view

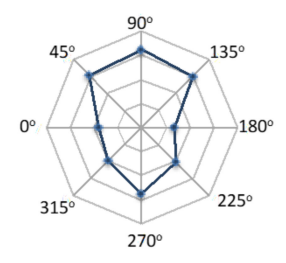

(d) splat perimeter height

Figure 5. A topographical map from 20-40 $\mu \mathrm{m}$ droplets measured by profilometry (a) in a 3D map of a $200 \mu \mathrm{m} \times 200 \mu \mathrm{m}$ section and (b) in a photosimulation view. A more detailed analysis of the circled Splat shows (c) a profile view of a Splat at a $0^{\circ}-180^{\circ}$ section, and (d) the Splat height at different rotations. The orientation of $(\mathbf{b})$ and (d) are identical to show the influence of surrounding Splats on the measured Splat height. The webs on the radar plot start at 0 , with height increments of $4 \mu \mathrm{m}$.

Splat height at the circumference varied in response to the underlying surface contour and surrounding splat proximity. A line profile on a close-to-horizontal reference plane showed a similar splat height at opposite ends (orientation $0^{\circ}-180^{\circ}$; Figure $5 \mathrm{c}$ ). Line profiles taken at other orientations 
-through the center of the splat (marked in Figure 5b)-displayed different splat heights at the opposite ends (Figure 5d). A shorter-perimeter splat was registered where there was interference from neighboring splats; as seen at $0^{\circ}, 180^{\circ}, 225^{\circ}$ and $315^{\circ}$ (Figure $5 \mathrm{~d}$ ). Conversely, taller splats were recorded when the reference line outside the splat was at a lower point. The highlighted splat (Figure 5a,b) formed on a ridge leading to an apparent higher splat boundary at $45^{\circ}, 90^{\circ}, 135^{\circ}$ and $270^{\circ}$.

Splat height increased with a larger splat diameter (Figure 6). Small $15 \mu \mathrm{m}$ diameter splats were $3 \mu \mathrm{m}$ high, while a splat with a diameter of $80 \mu \mathrm{m}$ (about 5-times larger) was $7.8 \mu \mathrm{m}$ high (2.6-times higher). This trend was also observed for coatings made from 20-40 $\mu \mathrm{m}$ and $40-60 \mu \mathrm{m}$ powders. Splat height was difficult to measure with large splats due to interference from the underlying irregularities.

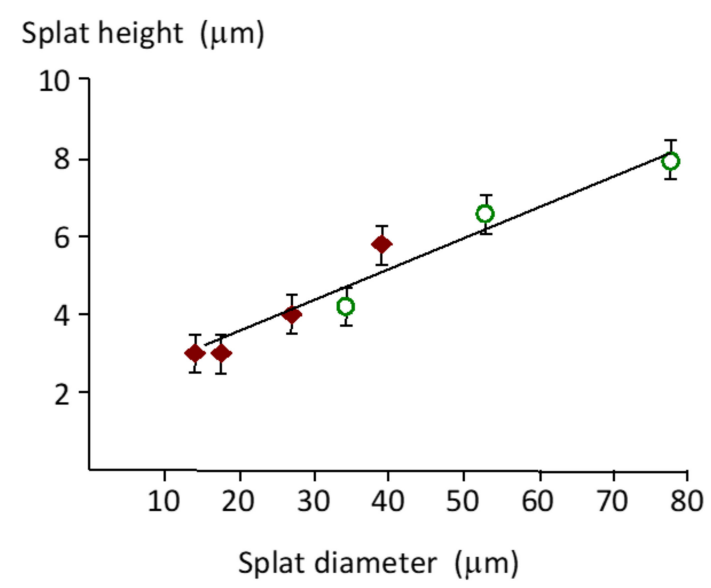

Figure 6. Variation of splat height (h) with splat diameter (d), according to the line of best fit, $h=0.083 d+1.743\left(R^{2}=0.98\right)$ in the splat size range of $15 \mu \mathrm{m}$ to $80 \mu \mathrm{m}$. Data with diamond symbols were sourced from the coating made from $20-40 \mu \mathrm{m}$ particles, and the data with open circles came from the coating made from $40-60 \mu \mathrm{m}$ particles.

The two stylus/probe measurement methods—profilometry and atomic force microscopy-recorded the splat geometry at different levels of sensitivity. The profilometer stylus with a large $90^{\circ}$ included angle could not accurately determine the splat perimeter shape, producing a gradual decrease in height. The splat edge geometry was more accurately reflected with the $18^{\circ}$ included angle (i.e., $9^{\circ}$ half angle for scans at $90^{\circ}$ angle relative to the cantilever orientation) of the AFM tip, Figure 7. The average splat height was determined to be $1 \pm 0.6 \mu \mathrm{m}$ for a $40 \mu \mathrm{m}$ splat (see a-a' traverse in Figure 7B). This splat appeared to be seated in an underlying cavity, with the line a-a' representing the highest points.
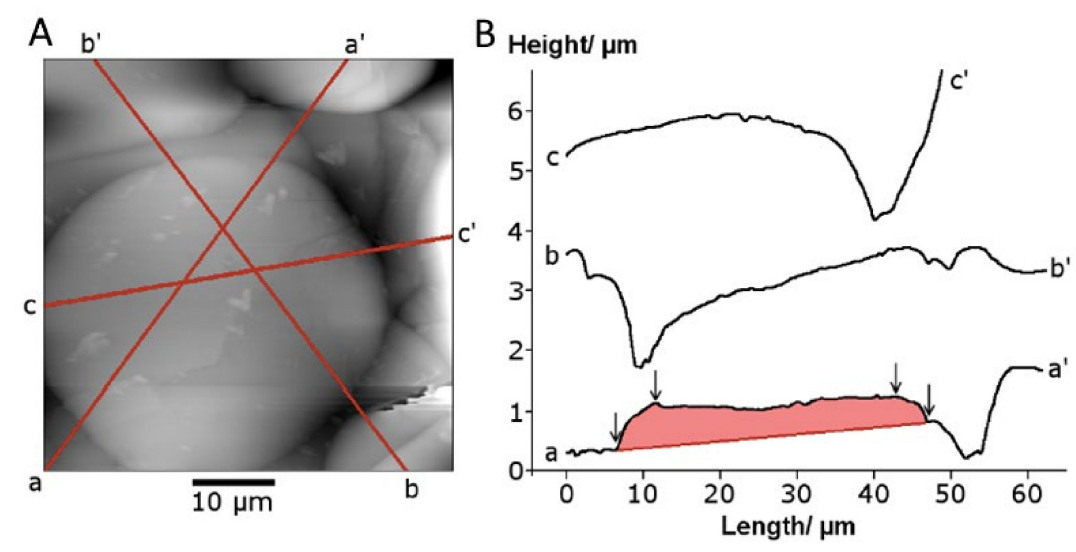

Figure 7. AFM scans of (A) a splat and (B) the traverse lines (a,b and c) to produce profiles of the splat shown as traces $a-a^{\prime}, b-b^{\prime}$ and $c-c^{\prime}$ of a splat. The shaded trace $a-a^{\prime}$ was used for splat height analysis. 
Two types of splat profiles were observed for smaller splats: a flattened disk with a raised center and splats with a lowered center compared to the edges. A raised center, comparable to a flattened hemisphere, was more frequently observed for splats on a relatively flat background. The splat with a flat surface was formed on a slope $\left(b^{\prime}-b\right.$ in Figure 7$)$ that preferentially directs the center of mass towards the lowest point.

Splats larger than $50 \mu \mathrm{m}$ displayed an undulating surface reflecting the underlying coating surface - a raised center could not be detected. If a raised center was formed, then this blended in with the many undulations on the splat surface.

\subsection{Crystal Size}

Variation in the crystal size occurred both in differently sized splats and also within the splat. Small splats showed an average crystal size of $200 \mu \mathrm{m}$ (made from 20-40 $\mu \mathrm{m}$ particles), but larger splats exhibited an average of $260 \mu \mathrm{m}$-sized crystals (from $63-80 \mu \mathrm{m}$ particles), Table 1 . The crystal size was relatively uniform over the majority of the splat, Figure 8. Within a small splat the central region (position C) showed significantly larger crystals $(225 \mu \mathrm{m})$ compared to the very edge (position E) where crystals with a diameter of $100 \mu \mathrm{m}$ were observed. The central area of the splat is where crystal growth occurs first [26], explaining the larger crystals.

Table 1. Crystal size for splats made from differently sized particles, and within a splat at positions E, $\mathrm{T}$ and $\mathrm{C}$ (median \pm interquartile range, $P<0.05$ indicates differences between measurement groups outside the rejection region for a significance level of $P=0.05$ ).

\begin{tabular}{ccccc}
\hline $\begin{array}{c}\text { Particle Size } \\
(\boldsymbol{\mu m})\end{array}$ & $\mathbf{N}$ & $\begin{array}{c}\text { Crystal Size } \\
(\mathbf{n m})\end{array}$ & IQR & $\boldsymbol{P}<\mathbf{0 . 0 5}$ \\
\hline $20-40$ & 27 & 200 & 0.038 & $40-60,60-80$ \\
Edge, E & 10 & 100 & 0.012 & C, T \\
Transition, T & 11 & 215 & 0.020 & $\mathrm{E}$ \\
Center, C & 6 & 225 & 0.016 & $\mathrm{E}$ \\
$40-60$ & 33 & 240 & 0.032 & $20-40$ \\
$60-80$ & 19 & 260 & 0.063 & $20-40$ \\
\hline
\end{tabular}

A

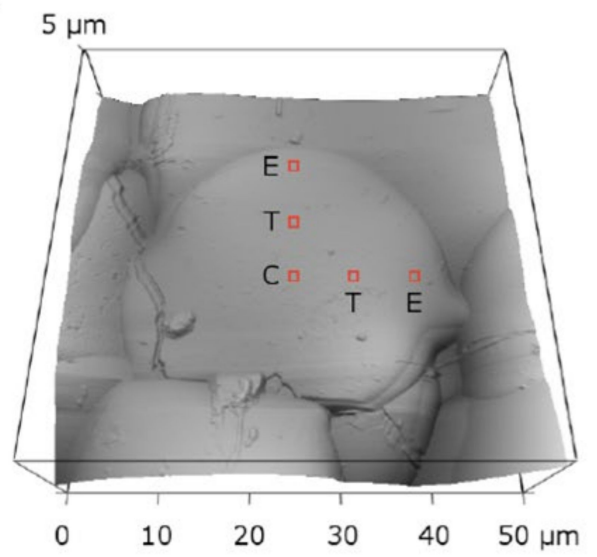

B

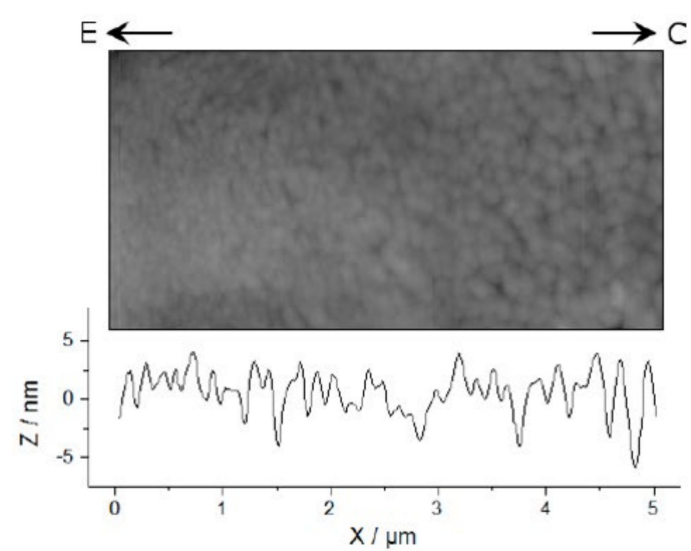

Figure 8. A splat visualized by $\operatorname{AFM}(\mathbf{A})$ outlining three analysis positions and (B) showing an enlarged view.

Along the direction from the center $(\mathrm{C})$ to the edge (E) to reveal a gradual increase in crystal size towards the center. 


\section{Discussion}

The combination of homogeneous splats and detailed analysis techniques allowed more detailed characterization. Structure (surface topography, splat topography and crystal structure), chemistry (crystal structure and bonding) and electrical potential will be discussed in turn and the information collated to reveal the structural and chemical hierarchy within coating surfaces. Splats will be referred to as hydroxyapatite splats since the oxyapatite quickly takes up water vapor to form a thin outer hydroxylated film, but reference will be made oxyapatite or hydroxyapatite when the splat is discussed in more detail.

\subsection{Topography of Hydroxyapatite Splats}

While previous work used roughness to describe the coating smoothness $[27,28]$, this generic measure of surface undulations has not identified the individual splat and finer attributes of the splat. Initial work on thermally sprayed materials was directed at ensuring rounded splats, without splashing [29-32]; this work has shown that the true surface-splats on titanium have a rim at the edge [33]—splats deposited directly on other HAp splats are flat in comparison.

It is interesting to note a linear increase in the splat height with the splat diameter for the small splats investigated here. Larger particles had an unmelted core, and formed a splat with a higher center and so made it difficult to measure the splat height. Further reports should consider mapping the splat microstructure (crystal size, crystal orientation and chemistry) with the particle size.

The recorded splat shape depends on the scanning probe internal angle. A large included angle for the profilometer did not accurately measure the splat shape. Previous measurement with a Berkovich probe on a nanoindentor with a larger included angle showed a tapered edge [34], similar in shape to the splat edge recorded with the profilometer probe, Figure 6. In the 3D map or photosimulation made from the profilometer data, all splats appeared tapered. The image from an AFM probe with the small included angle showed a steeper edge, more representative of the true situation. The higher sensitivity of the AFM tip has also been reported for inkjet-printed, splat-shaped deposits [35]. The rounded splat edge shown by the AFM probe has also been found in cross-sections of focused-ion-beam-prepared splats [36].

\subsection{Variations in Chemistry on the Coating Surface}

Both oxyapatite and hydroxyapatite were identified from the different unit cell heights as shown by the X-ray diffraction doublet, and from the two types of phosphate bonding in the Raman peak. The XRD peak doublet implies that a hydroxyapatite-oxyapatite solid solution did not form, that could otherwise be observed as a single, wide peak. A single, wide peak is not expected due to $\mathrm{OH}^{-}$removal from the droplet outer layer followed by rapid solidification as oxyapatite. Oxyapatite then takes up water vapor on the surface and adds a surface hydroxyapatite layer to supplement any hydroxyapatite that may already be present in the splat core.

There are two distinguishable scenarios that could lead to distinct oxyapatite and hydroxyapatite regions. In the first situation, the completely dehydroxylated droplet flattens, solidifies as oxypatite and then incorporates water from the atmosphere to form a hydroxyapatite shell. This agrees with the findings from earlier studies showing a greater $\mathrm{OH}^{-}$concentration on the coating surface [24]. In the second situation, the core of the droplet retains hydroxyl ions, unable to release $\mathrm{OH}^{-}$ions through the larger droplet diameter: the partially dehydroxylated droplet solidifies as oxyapatite and the outer layer converts to hydroxyapatite as water is included from the atmosphere. The first scenario leads to a hydroxyapatite skin surrounding an oxyapatite core, but the second scenario depicts a striated or banded structure to reflect the $\mathrm{OH}^{-}$retained in the core and incorporated on the surface.

For the interpretation of the distribution of oxyapatite and hydroxyapatite it is important to consider that (1) the edge of the splat will always have the lowest $\mathrm{OH}^{-}$content and (2) smaller splats will be more unlikely to contain $\mathrm{OH}^{-}$ions in the splat.

A previous model based on X-ray diffraction patterns of the crushed coating, and not an analysis of the splat as conducted here, inconclusively suggested oxyhydroxyapatite at the core [37]. Our results 
do not support those findings. The results of this study clearly show two distinct spatial regions in the splat: an oxyapatite-rich region and a hydroxyapatite-rich region.

\subsection{Surface Electrical Potential}

The larger electrical surface potential from smaller splats could be explained by two factors. The first source of the field could come from oxyapatite [38]. Oxyapatite consists of alternative stacking of defects and $\mathrm{O}^{2-}$ ions in columns within the unit cell [39]. This alternating stacking arrangement with a negative charge at one height and a neutral charge at the other level, stacked together in the column of the unit cell, is similar to a dipole and provides an overall negative field. Since smaller splats contain more oxyapatite, one expects a higher surface electrical potential in smaller splats. The contributing factor to the surface electrical potential could arise from stacking of aligned $\mathrm{OH}^{-}$ions in the outer layer. The ordering of the $\mathrm{OH}^{-}$ions may occur spontaneously under the influence of the underlying negative field in oxyapatite, causing the hydrogen to enter the column first and be attracted by the underlying negative charge. Consequently, the supposedly oriented $\mathrm{OH}^{-}$ion layer forms a dielectric plug in the outer surface, and delays continued $\mathrm{OH}^{-}$inclusion deeper into oxyapatite over time. This change in $\mathrm{OH}^{-}$ content with depth-over-time needs more refined tools such as scanning near-field optical microscopy (SNOM) for the simultaneous measurement of the $\mathrm{OH}^{-}$content and the surface electrical potential [40].

Given the observation of a larger surface electrical potential from smaller splats, it would appear that the origin of the potential in thermal-spray coatings is associated with oxyapatite, with a concomitant contribution from the outer hydroxyapatite layer. This is best illustrated in a comparison of a small splat and a large splat (normalized to emphasize the $\mathrm{OH}^{-}$-rich and the $\mathrm{OH}^{-}$-depleted layers) to show the chemically different areas and the resulting surface electrical potential. A stronger field is expected from an oxyapatite core and this is shown with larger arrows. Smaller arrows from the splat with a hydroxyapatite core are assumed to arise from the randomly oriented $\mathrm{OH}^{-}$ions in the core, thus creating an insulator that dampens the electrical field effect from the underlying oxyapatite layer, Figure 9.

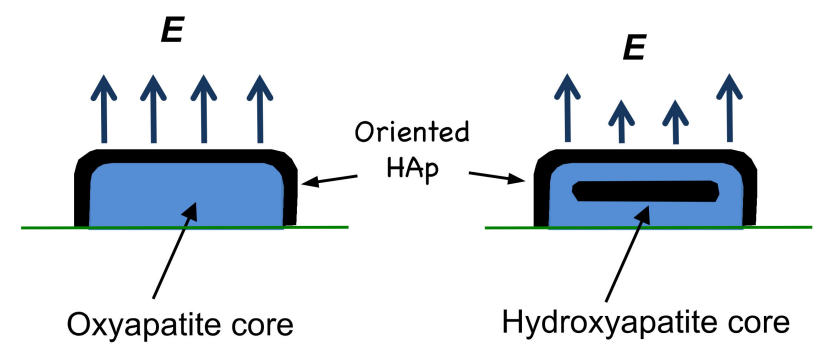

Figure 9. The hydroxyapatite and oxyapatite regions within a splat, where an oxyapatite core occurs for smaller splats and a hydroxyapatite core is found in larger splats. Both splats are normalized for ease of comparison. An 80- $\mu$ m-sized droplet, depicted to the right with a HAp core, would be 4.3-times larger in diameter and a 3-times higher, if extrapolated from the data shown in Figure 8.

\subsection{Structural and Chemical Hierarchy}

The hierarchy, both structural and chemical, will impact the charge created within the coating, that has been shown to impact bone formation [41]. A knowledge of factors that influence the hierarchy will add an extra level of control for the design of coatings. A model is proposed for the hierarchy in the coatings.

Characterization of splat-designed coatings suggested hierarchy over five orders of magnitude from the angstrom level to the millimeter level [42]. A hierarchy was found both in structure and chemistry. This hierarchy stemmed from the control of particle processing (particle heating, splat size) and led to changes in crystal characteristics within the splat $[42,43]$. Structural hierarchy spanned from $\mathrm{OH}^{-}$dipole arrangement in the unit cell at the angstrom level to the stacking of splats within the coating at the macrolevel (Figure 10), also seen by others [43]. Splats consisted of oriented crystals comprising of both oxyapatite and hydroxyapatite layers. The HAp layer on the splat surface arose from surface rehydroxylation [44]. The HAp lenticular layer in the core of the splat-only reported in 
larger splats-resulted from retained $\mathrm{OH}^{-}$ions in the splat core (Figures 8 and 9). The HAp in the core is expected to have a disorganized $\mathrm{OH}^{-}$ion arrangement. Ordering of $\mathrm{O}^{2}$ and vacancies in the oxyapatite layer is surmised to cause ordering of $\mathrm{OH}^{-}$ions in the upper/outer HAp layer, as indicated by the larger electrical surface potential, Figure 3.

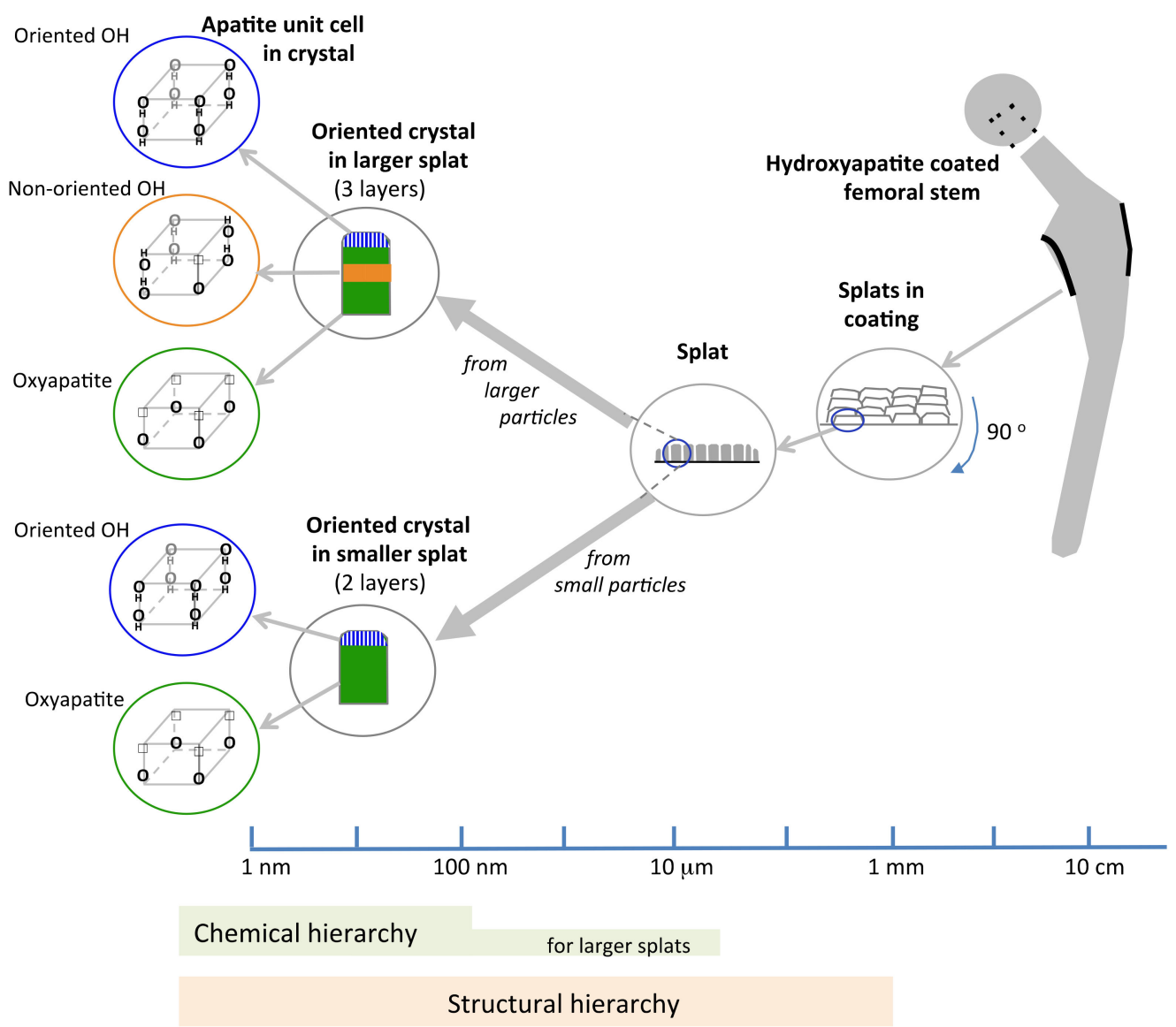

Figure 10. Proposed schema summarizing the five levels of structural hierarchy and three levels of chemical hierarchy in hydroxyapatite-coatings made from different sized splats.

The structural hierarchy includes $\mathrm{OH}^{-}$orientation, the crystal structure, layers within the crystal, crystal assembly within the splat and splat assembly; the chemical hierarchy covers fewer successive levels of order. Smaller droplets are totally dehydroxylated before creating a splat and will display chemical order up to the crystal level. Larger droplets retain an $\mathrm{OH}^{-}$core and will manifest a variation along the splat diameter, Figure 8, extending the chemical hierarchy up to the splat level, Figure 10, also reported by Tanaka et al. [45]. Above a critical particle size, the hierarchy increases.

This discussion assumes that phosphate is not preferentially volatilized from the outer droplet layer.

In the present study, the hierarchy is created by $\mathrm{OH}^{-}$removal during particle heating, the assembly of aligned oxyapatite crystals in the microstructure during solidification and a self-assembly of $\mathrm{OH}^{-}$ions from the adsorbed water in the air after deposition. To orchestrate these separate-but-interdependent events requires control over a series of thermodynamically and kinetically driven processes in a short time. The optimization of events over a time-scale and length-scale has provided the first step to hierarchically designed implant materials. 


\subsection{Design Opportunities for Hydroxyapatite Implants}

Previous coating designs were only required to satisfy requirements of hydroxyapatite purity, hydroxyapatite crystallinity and coating adhesion [46]. Unmelted particles have contributed to particle release [47] followed by signs of inflammation [48-51]. A designed microstructure can avoid these potential problems and provide a functional biocompatible material.

A homogeneous coating with oriented crystals has shown better remodeling based on osteoclast resorption: a comparison between dentine, a hydroxyapatite coating with oriented crystals, and a sintered hydroxyapatite showed a similar osteoclast population on dentine and thermally sprayed hydroxyapatite [17]. The reason for resorption remains to be determined from the nanotopography, grain size, oriented crystals and surface electrical potential.

An implant surface charge made by structural and chemical hierarchy could be used to favor protein attachment [52], cell adhesion [53] and bone growth [10] and provide docking capabilities for biological species or drugs. Adjusting the surface charge of hydroxyapatite can support protein attachment. Previous attempts for attaching proteins onto hydroxyapatite have charged hydroxyapatite by initial attachment of selected amino acids [54]. Perhaps designing hydroxyapatite to include a surface charge may be a better and simpler option for achieving protein attachment, but this remains speculation at this moment.

\section{Conclusions}

Homogeneous splats have allowed more detailed characterization of coatings with attention to the splat shape, splat thickness, splat edge, splat crystal size, splat chemistry and electrical surface potential.

Different levels of hierarchy were found within the splat-assembled coatings at the structural and chemical level. Firstly, all splats exhibited relatively even thickness, disk-like structures with steep edges. Crystals within splats were oriented and appeared to be twice as large in the middle of the splat compared to the splat edge. A small increase in overall crystal size occurred for larger splats, but this was less marked than the change in crystal size with position in the splat. At the lowest level of structural hierarchy, layers of oxyapatite and hydroxyapatite were found from the change in unit cell dimensions by $\mathrm{X}$-ray diffraction and chemical bonding by Raman spectroscopy.

Chemical hierarchy appears horizontally and vertically within the splat. An oxyapatite core in smaller splats indicated complete removal of hydroxyl ions during heating, but a hydroxyapatite core in larger splats only showed partial hydroxyl depletion. The greater surface electrical potential from smaller splats suggests that oxyapatite forms a dielectric that induces hydroxyl ion orientation on the splat surface.

Author Contributions: Conceptualization, K.A.G. Methodology, formal analysis, L.P.-L., C.P., M.K. Investigation, L.P.-L., C.P., M.K. Data curation, K.A.G.; L.P.-L., C.P., M.K. Writing-original draft preparation, K.A.G. Writing_review and editing, all. Supervision, K.A.G., H.J.H. Project administration, K.A.G., H.J.H. Funding acquisition, K.A.G. All authors have read and agreed to the published version of the manuscript.

Funding: This research was supported by the M-ERA Net project grant named Signalling Implant, ES RTD/2017/4. This study extends the initiative of a previously funded project grant PIRG05-GA-2009-249306 Refined Step.

Acknowledgments: Splats were produced at Monash University by KAG. The design of the experiment and the coatings were produced by KAG, microtopography measured by MK, AFM studies conducted and analyzed by CP, XRD patterns and Raman spectra taken by LP, but Kelvin probe AFM taken by Edijs Freimanis. The profilometer was used at Riga Technical University, AFM at University of Oslo.

Conflicts of Interest: The authors declare no conflict of interest. 


\section{References}

1. Li, D.; Zheng, Q.; Wang, Y.W.; Chen, H. Combining surface topography with polymer chemistry: Exploring new interfacial biological phenomena. Polym. Chem. 2014, 5, 14-24. [CrossRef]

2. Ponche, A.; Bigarelle, M.; Anselme, K. Relative influence of surface topography and surface chemistry on cell response to bone implant materials. Part 1: Physico-chemical effects. P. I. Mech. Eng. H. 2010, 224, 1471-1486. [CrossRef] [PubMed]

3. Rahmati, M.; Silva, E.A.; Reseland, J.E.; Heyward, C.A.; Haugen, H.J. Biological responses to physicochemical properties of biomaterial surface. Chem. Soc. Rev. 2020, 49, 5178-5224. [CrossRef] [PubMed]

4. Taxt-Lamolle, S.F.; Rubert, M.; Haugen, H.J.; Lyngstadaas, S.P.; Ellingsen, J.E.; Monjo, M. Controlled electro-implementation of fluoride in titanium implant surfaces enhances cortical bone formation and mineralization. Acta Biomater. 2010, 6, 1025-1032. [CrossRef] [PubMed]

5. Reczyńska, K.; Wrona, M.; Tiainen, H.; Haugen, H.; Pamuła, E. The influence of sintering conditions on microstructure and mechanical properties of titanium dioxide scaffolds for the treatment of bone tissue defects. Acta Bioeng. Biomech. 2015, 17, 3-9.

6. Thevenot, P.; Hu, W.J.; Tang, L.P. Surface chemistry influences implant biocompatibility. Curr. Top. Med. Chem. 2008, 8, 270-280.

7. Lu, T.; Qiao, Y.Q.; Liu, X.Y. Surface modification of biomaterials using plasma immersion ion implantation and deposition. Interface Focus 2012, 2, 325-336. [CrossRef]

8. Frank, M.J.; Walter, M.S.; Tiainen, H.; Rubert, M.; Monjo, M.; Lyngstadaas, S.P.; Haugen, H.J. Coating of metal implant materials with strontium. J. Mater. Sci. Mater. 2013, 24, 2537-2548. [CrossRef]

9. Hallab, N.J.; Bundy, K.J.; O'Connor, K.; Clark, R.; Moses, R.L. Cell adhesion to biomaterials: Correlations between surface charge, surface roughness, adsorbed protein, and cell morphology. J. Long. Term. Eff. Med. 1995, 5, 209-213.

10. Kobayashi, T.; Nakamura, S.; Yamashita, K. Enhanced osteobonding by negative surface charges of electrically polarized hydroxyapatite. J. Biomed. Mater. Res. 2001, 57, 477-484. [CrossRef]

11. Ehrenfest, D.M.D.; Coelho, P.G.; Kang, B.S.; Sul, Y.T.; Albrektsson, T. Classification of osseointegration implant surfaces: Materials, chemistry and topography. Trends. Biotechnol. 2010, 28, 198-206. [CrossRef] [PubMed]

12. Frank, M.J.; Walter, M.S.; Bucko, M.M.; Pamula, E.; Lyngstadaas, S.P.; Haugen, H.J. Polarization of modified titanium and titanium-zirconium creates nano-structures while hydride formation is modulated. Appl. Surf. Sci. 2013, 282, 7-16. [CrossRef]

13. Frank, M.J.; Walter, M.S.; Lyngstadaas, S.P.; Wintermantel, E.; Haugen, H.J. Hydrogen content in titanium and a titanium-zirconium alloy after acid etching. Mat. Sci. Eng. C Mater. 2013, 33, 1282-1288. [CrossRef] [PubMed]

14. Dumbleton, J.; Manley, M.T. Current concepts review - Hydroxyapatite-coated prostheses in total hip and knee arthroplasty. J. Bone Joint Surg. 2004, 86, 2526-2540. [CrossRef] [PubMed]

15. Prevey, P.S. X-ray diffraction characteriztion of crystallinity and phase composition in plasma-sprayed hydroxyapatite coatings. J. Therm. Spray Technol. 2000, 9, 369-376. [CrossRef]

16. Gross, K.A.; Berndt, C.C.; Herman, H. Amorphous phase formation in plasma-sprayed hydroxyapatite coatings. J. Biomed. Mater. Res. 1998, 39, 407-414. [CrossRef]

17. Gross, K.A.; Muller, D.; Lucas, H.; Haynes, D.R. Osteoclast resorption of thermal spray hydroxyapatite coatings is influence by surface topography. Acta Biomat. 2012, 8, 1948-1956. [CrossRef]

18. Salimijazi, H.R.; Pershin, L.; Coyle, T.W.; Mostaghimi, J.; Chandra, S.; Lau, Y.C.; Rosenzweig, L.; Moran, E. Effect of droplet characteristics and substrate surface topography on the final morphology of plasma-sprayed zirconia single splats. J. Therm. Spray Technol. 2007, 16, 291-299. [CrossRef]

19. Cizek, J.; Khor, K.A. Role of in-flight temperature and velocity of powder particles on plasma sprayed hydroxyapatite coating characteristics. Surf. Coat. Technol. 2012, 206, 2181-2191. [CrossRef]

20. Vardelle, M.; Vardelle, A.; Leger, A.C.; Fauchais, P.; Gobin, D. Influence of particle parameters at impact on splat formation and solidification in plasma spraying processes. J. Therm. Spray Technol. 1995, 4, 50-58. [CrossRef]

21. Schade, M.; Varlamova, O.; Reif, J.; Blumtritt, H.; Erfurth, W.; Leipner, H.S. High-resolution investigations of ripple structures formed by femtosecond laser irradiation of silicon. Anal. Bioanal Chem. 2010, 396, 1905-1911. [CrossRef] [PubMed] 
22. Garskaite, E.; Gross, K.A.; Yang, S.W.; Yang, T.C.K.; Yang, J.C.; Kareiva, A. Effect of processing conditions on the crystallinity and structure of carbonated calcium hydroxyapatite (CHAp). Cryst. Eng. Comm. 2014, 16, 3950-3959. [CrossRef]

23. Raynaud, S.; Champion, E.; Bernache-Assollant, D.; Laval, J.P. Determination of calcium/phosphorus atomic ratio of calcium phosphate apatites using X-ray diffractometry. J. Am. Ceram. Soc. 2001, 84, 359-366. [CrossRef]

24. Gross, K.A.; Berndt, C.C.; Dinnebier, R.; Stephens, P. Oxyapatite in hydroxyapatite coatings. J. Mater. Sci. 1998, 33, 3985-3991. [CrossRef]

25. Demnati, I.; Parco, M.; Grossin, D.; Fagoaga, I.; Drouet, C.; Barykin, G.; Combes, C.; Braceras, I.; Goncalves, S.; Rey, C. Hydroxyapatite coating on titanium by a low energy plasma spraying mini-gun. Surf. Coat. Technol. 2012, 206, 2346-2353. [CrossRef]

26. Bianchi, L.; Denoirjean, A.; Blein, F.; Fauchais, P. Microstructural investigation of plasma-sprayed ceramic splats. Thin Solid Films 1997, 299, 125-135. [CrossRef]

27. Montanaro, L.; Arciola, C.R.; Campoccia, D.; Cervellati, M. In vitro effects on MG63 osteoblast-like cells following contact with two roughness-differing fluorohydroxyapatite-coated titanium alloys. Biomaterials 2002, 23, 3651-3659. [CrossRef]

28. Hahn, B.D.; Park, D.S.; Choi, J.J.; Ryu, J.; Yon, W.H.; Choi, J.H.; Kim, J.W.; Cho, Y.L.; Park, C.; Kim, H.E.; et al. Preparation and in vitro characterization of aerosol-deposited hydroxyapatite coatings with different surface roughnesses. Appl. Surf. Sci. 2011, 257, 7792-7799. [CrossRef]

29. Fauchais, P.; Fukumoto, M.; Vardelle, A.; Vardelle, M. Knowledge concerning splat formation: An invited review. J. Therm. Spray Technol. 2004, 13, 337-360. [CrossRef]

30. Dhiman, R.; McDonald, A.G.; Chandra, S. Predicting splat morphology in a thermal spray process. Surf. Coat. Technol. 2007, 201, 7789-7801. [CrossRef]

31. Pasandideh-Fard, M.; Pershin, V.; Chandra, S.; Mostaghimi, J. Splat shapes in a thermal spray coating process: Simulations and experiments. J. Therm. Spray Technol. 2002, 11, 206-217. [CrossRef]

32. Fukumoto, M.; Yamaguchi, T.; Yamada, M.; Yasui, T. Splash splat to disk splat transition in plasma-sprayed metallic materials. J. Therm. Spray Technol. 2007, 16, 905-912. [CrossRef]

33. Gross, K.A.; Young, C.J.; Beck, M.A.; Keebaugh, E.W.; Bronts, T.J.; Saber-Samandari, S.; Riley, D.P. Characterisation and dissolution of functionalised amorphous calcium phosphate biolayers using single splat technology. Acta Biomat. 2011, 77, 2270-2275. [CrossRef] [PubMed]

34. Saber-Samandari, S.; Gross, K.A. Nanoindentation on the surface of thermally sprayed coatings. Surf. Coat. Technol. 2009, 203, 3516-3520. [CrossRef]

35. Xu, R.M.; Fleming, P.D.; Pekarovicova, A.; Bliznyuk, V. The effect of ink jet paper roughness on print gloss. J. Imag. Sci. Techn. 2005, 49, 660-666. [CrossRef]

36. Saber-Samandari, S.; Alamara, K.; Saber-Samandari, S. Calcium phosphate coatings: Morphology, micro-structure and mechanical properties. Ceram. Internat. 2014, 40, 563-572. [CrossRef]

37. Carayon, M.T.; Lacout, J.L.S. Study of the Ca/P atomic ratio of the amorphous phase in plasma-sprayed hydroxyapatite coatings. J. Solid State Chem. 2003, 172, 339-350. [CrossRef]

38. Dai, L.; Yang, G.X.; Zhou, H.Z.; He, Z.X.; Li, Y.H.; Wang, L. Mixed potential NH3 sensor based on Mg-doped lanthanum silicate oxyapatite. Sensor Actuat. B Chem. 2016, 224, 356-363. [CrossRef]

39. Elliott, J.C. Structure and Chemistry of the Apatites and Other Calcium Orthophosphates; Elsevier: Amsterdam, The Netherlands, 2013.

40. Drukteinis, S.E. Engineering of Pulsed Laser Deposited Calcium Phosphate Biomaterials in Controlled Atmospheres. Ph.D. Thesis, University of Alabama at Birmingham, Birmingham, AL, USA, 2012.

41. Ito, S.; Nakamura, S.; Kobayashi, T.; Shinomiya, K.; Yamashita, K. Effect of electrical polarization of hydroxyapatite ceramics on new bone formation. Calc. Tissue. Int. 2006, 78, 133-142. [CrossRef]

42. Sampath, S.; Jiang, X.Y.; Matejicek, J.; Leger, A.C.; Vardelle, A. Substrate temperature effects on splat formation, microstructure development and properties of plasma sprayed coatings Part I: Case study for partially stabilized zirconia. Mat. Sci. Eng. A Struct. 1999, 272, 181-188. [CrossRef]

43. Li, H.; Khor, K.A.; Cheang, P. Effect of steam treatment during plasma spraying on the microstructure of hydroxyapatite splats and coatings. J. Therm. Spray Technol. 2006, 15, 610-616. [CrossRef]

44. Dugas, V.; Chevalier, Y. Surface hydroxylation and silane grafting on fumed and thermal silica. J. Colloid Interf. Sci. 2003, 264, 354-361. [CrossRef] 
45. Tanaka, H.; Chikazawa, M.; Kandori, K.; Ishikawa, T. Influence of thermal treatment on the structure of calcium hydroxyapatite. Phys. Chem. Chem. Phys. 2000, 2, 2647-2650. [CrossRef]

46. Zhou, C.C.; Ye, X.J.; Fan, Y.J.; Ma, L.; Tan, Y.F.; Qing, F.Z.; Zhang, X.D. Biomimetic fabrication of a three-level hierarchical calcium phosphate/collagen/hydroxyapatite scaffold for bone tissue engineering. Biofabrication 2014, 6, 035013. [CrossRef]

47. Xiao, Y.Q.; Ren, E.Z.; Hu, M.Y.; Liu, K. Effect of Particle In-Flight Behavior on the Microstructure and Fracture Toughness of YSZ TBCs Prepared by Plasma Spraying. Coatings 2018, 8, 309. [CrossRef]

48. Gross, K.A.; Ray, N.; Rokkum, M. The contribution of coating microstructure to degradation and particle release in hydroxyapatite coating prostheses. J. Biomed. Mater. Res. 2002, 63, 106-114. [CrossRef]

49. Velard, F.; Laurent-Maquin, D.; Guillaume, C.; Bouthors, S.; Jallot, E.; Nedelec, J.M.; Belaaouaj, A.; Laquirriere, P. Polymorphonuclear neutrophil response to hydroxyapatite particles, implication in acute inflammatory reaction. Acta Biomater. 2009, 5, 1708-1715. [CrossRef]

50. Rahbek, O. The Influence of Hydroxyapatite Coating on the Peri-implant Migration of Polyethylene Particles. Ph.D. Thesis, Faculty of Health Sciences, University of Aarhus, Aarhus, Denmark, 2002.

51. Rokkum, M.; Brandt, M.; Bye, K.; Hetland, K.R.; Waage, S.; Reigstad, A. Polyethylene wear, osteolysis and acetabular loosening with an HA coated hip prostheseis. A follow-up of 94 consecutive arthoplasties. J. Bone Jt. Surg. 1999, 81, 582-589. [CrossRef]

52. Zhu, H.G.; Ji, J.; Tan, O.G.; Barbosa, M.A.; Shen, J.C. Surface engineering og poly (DL-lactide) via electrostratic self-assembly of extracellular matrix-like molecules. Biomacromolecules 2003, 4, 378-386. [CrossRef]

53. Ohgaki, M.; Kizuki, T.; Katsura, M.; Yamashita, K. Manipulation of selective cell adhesion and growth by surface charges of electrically polarized hydroxyapatite. J. Biomed. Mater. Res. 2001, 57, 366-373. [CrossRef]

54. Lee, W.H.; Loo, C.Y.; Van, K.L.; Zavgorodniy, A.V.; Rohanizadeh, R. Modulating protein adsorption onto hydroxyapatite particles using different amino acis treatments. J. R. Soc. Interface 2012, 9, 918-927. [CrossRef] [PubMed]

(C) 2020 by the authors. Licensee MDPI, Basel, Switzerland. This article is an open access article distributed under the terms and conditions of the Creative Commons Attribution (CC BY) license (http://creativecommons.org/licenses/by/4.0/). 